\title{
Understanding the Biological Basis of Glioblastoma Patient-derived Spheroids
}

\author{
KAROLÍNA TURNOVCOVA ${ }^{1 \#}$, DANA MAREKOVA ${ }^{1,2 \#}$, TOLGA SURSAL $^{3}$, \\ MARKETA KRUPOVA ${ }^{4}$, RONAN GANDHI ${ }^{3}$, PETR KRUPA ${ }^{1,5}$, RADEK KAISER $^{6}$, \\ VIT HERYNEK $^{7}$, DAVID NETUKA ${ }^{6}$, PAVLA JENDELOVA ${ }^{1,2}$ and MEENA JHANWAR-UNIYAL ${ }^{3}$ \\ ${ }^{1}$ Department of Neuroregeneration Institute of Experimental Medicine \\ Czech Academy of Science, Prague, Czech Republic; \\ ${ }^{2}$ Second Faculty of Medicine, Charles University, Prague, Czech Republic; \\ ${ }^{3}$ Department of Neurosurgery, New York Medical College/Westchester Medical Center, Valhalla, NY, U.S.A.; \\ ${ }^{4}$ The Fingerland Department of Pathology, Faculty of Medicine and University Hospital in Hradec Kralové, \\ Charles University, Hradec Kralové, Czech Republic; \\ ${ }^{5}$ Department of Neurosurgery Faculty of Medicine and University Hospital in Hradec Kralove, \\ Charles University, Hradec Kralove, Czech Republic; \\ ${ }^{6}$ Department of Neurosurgery and Neurooncology, First Faculty of Medicine, \\ Charles University and Military University Hospital, Prague, Czech Republic; \\ ${ }^{7}$ Center for Advanced Preclinical Imaging, First Faculty of Medicine, Charles University, Prague, Czech Republic
}

\begin{abstract}
Background/Aim: Resistance to glioblastoma (GB) therapy is attributed to the presence of glioblastoma stem cells (GSC). Here, we defined the behavior of GSC as it pertains to proliferation, migration, and angiogenesis. Materials and Methods: Human-derived GSC were isolated and cultured from GB patient tumors. Xenograft GSC were extracted from the xenograft tumors, and spheroids were created and compared with human GSC spheroids by flow cytometry, migration, proliferation, and angiogenesis assays. Oct3/4 and Sox2, GFAP, and Ku80 expression was assessed by immunoanalysis. Results: The xenograft model showed the formation of two different tumors with distinct characteristics. Tumors formed at 2 weeks were less aggressive with well-defined margins, whereas tumors formed in 5 months were diffuse and aggressive. Expression of Oct3/4 and Sox 2 was positive in both
\end{abstract}

This article is freely accessible online.

\#These Authors contributed equally to this study.

Correspondence to: Pavla Jendelova, Ph.D., Institute of Experimental Medicine Czech Academy of Science, Videnska 1083, 14220 Prague, Czech Republic. Tel: +420 241062828, e-mail: pavla.jendelova@iem.cas.cz; Meena Jhanwar-Uniyal, PhD, Department of Neurosurgery, New York Medical College, Valhalla, New York 10595, NY, U.S.A. Tel: +1 9145942513, e-mail: meena_jhanwar@nymc.edu

Key Words: Patient-derived spheroid, 2D culture, 3D culture, migration, proliferation, angiogenesis. human and xenograft GSC. Positive Ku80 expression in xenograft GSC confirmed their human origin. Human and xenograft GSC migrated vigorously in collagen and Matrigel, respectively. Xenograft GSC displayed a higher rate of migration and invasion than human GSC. Conclusion: Human GSC were more aggressive in growth and proliferation than xenograft GSC, while xenograft GSC had increased invasion and migration compared to human GSC. A simple in vitro spheroid system for GSC provides a superior platform for the development of precision medicine in the treatment of GB.

Glioblastoma (GB) is the most common primary brain tumor, with an incidence rate of 3.19 per 100,000 persons and a median age of 64 . It makes up about $15 \%$ of all intracranial neoplasms and about half of all primary malignant brain tumors. GB is the most common type of glioma, accounting for approximately $60 \%$ of all gliomas. Overall median survival is 8 months with a 5 -year survival rate of only $7.2 \%$, and in untreated patients there is a median survival of only 3 months (1). Glioblastomas are part of a larger group of intracranial neoplasms called diffuse gliomas. There are many subtypes of gliomas, but they are all grouped according to not only to histology, growth, and behavior but, also according to their genetics (e.g. IDH1 and IDH2). According to the recent WHO current histological definition, tumors with cytological atypia alone (i.e. diffuse astrocytomas) are considered grade II, those that also show anaplasia and mitotic activity (i.e. anaplastic astrocytomas) are considered grade III, and tumors that additionally show microvascular proliferation and/or necrosis are grade IV (2). 
Originally GB was classified as primary, also called de novo, or secondary, which have progressed from lower-grade gliomas (3, 4). Primary GB affects the elderly and is genetically characterized by EGFR amplification, PTEN mutation, and p16INK4a deletion; and secondary GB develops in younger age groups and gene abnormalities include mutations of TP53 and RB (5). The discovery of IDH mutations in astrocytomas (6) is also used to subdivide GB into clinically important categories. Recent genetic analysis, however, categorizes GB into 4 major distinct subgroups, namely classical, mesenchymal, proneural, and neural, based on their unique genetic profiles (7). GB is a fatal disease that remains poorly responsive to conventional treatments, maximal safe neurosurgical resection, chemotherapy, and radiotherapy. Most importantly, the recurrence of GB tumor manifests in close proximity to the tumor margin. This recurrence can also be attributed to the presence of glioblastoma stem cells (GSC). GSC are not only within the tumor but also in the region surrounding the tumor margin and even more distant areas $(8,9)$. In fact, the peritumoral area of GB consists of a blend of complex subtypes of cells, which supports GSC as well as formation of new blood vessels (10). It has been shown that ATRA-induced differentiation of GSC, facilitated by the activation of ERK1/2, renders them vulnerable to therapy. GSC are shown to propagate from one host to another (e.g. human to rat) and can be expanded into orthotopic xenograft models that recapitulate the original tumor. These stem cells, which are isolated from different tumors show very different response characteristics, suggesting an extensive intra-tumoral stem cell heterogeneity. Many studies have demonstrated that GSC shows resistance to therapies such as chemotherapy (e.g. temozolomide) and radiotherapy. The hallmark of GSC are alterations in numerous proto-oncogenes and tumor suppressor genes that have been associated with quiescence of GSC. Some of these genes include Bmi-1, Gfi1, PTEN, and p53 (4). Furthermore, the receptor tyrosine kinases (RTK), EGFR, as well as PTEN/Akt signaling have also been linked with the tumorigenesis of GB (11). Heterogeneity of GB tumors, characterized by various sets of genetic markers within the same tumor, suggests that a diverse range of neural stem and/ or progenitor cells may be responsible for originating the growth of GB recurrences. In fact, a recent single-cell RNA-seq analysis of GB tumors has defined that GSC contains inter-tumoral molecular and genomic heterogeneity (12). The presence of stem-like cells in brain tumor cultures was shown using molecular signaling (13). Other studies further extended these observations showing the presence of GSC, with CD133 positivity, within the tumor mass of GB and other brain tumors (14-16).

Establishing a suitable glioma model for experimentation always presents challenges. Cancer models, such as 2D cultured cell lines and cell-line-derived xenografts, have been shown to be helpful in studying treatments for GB. In this study, we explored the tumor xenograft model to better understand the nature of GSC as pertains to proliferation, migration, and angiogenesis of the tumor.

\section{Materials and Methods}

Patient tumors. Glioblastoma tumors were obtained from Military University Hospital, Prague, CZ /Neurosurgical Department of 1st Faculty of Medicine of Charles University following the guidelines and approval of the Institutional Review Board (IRB) with signed informed consent. The surgically removed tumor was placed into a sterile tube with normal saline with vancomycin $(2 \mathrm{~g} / \mathrm{l})$. Tumor tissue was washed with cold PBS and $8 \times 8 \times 8 \mathrm{~mm}$ pieces were cut out using the bioptic punch to allocate samples for immunohistochemistry (IHC); stored in 4\% paraformaldehyde, PFA); the rest of the tissue was processed for cell cultures. The histological features of tumors were obtained from the Department of Pathology, Military University Hospital Prague, Prague, Czech Republic. Genetic analysis of tumors showed abnormal p53, with IDH1- and positivity for ATRX.

Processing of tumor tissue. Minced tumor tissue was washed with PBS and mixed with trypsin/EDTA, collagenase I, hyaluronidase II, and accutase (Sigma-Aldrich, St. Louis, MO, USA) and incubated at $37^{\circ} \mathrm{C}$. The mixture was gently pipetted to obtain a smooth solution. The enzymatic reaction was terminated with FBS and filtered through 500,100, and $30 \mu \mathrm{m}$ cell strainers (PluriSelect, Life Science, Leipzig, Germany). Viability was then analyzed using Luna-FL (Logos Biosystems, Anyang-si, Gyeonggi-do, South Korea). The primary cell suspension was subjected to adherent culture, used for primary spheres, or stored in liquid nitrogen.

\section{In vivo study}

Transplantation of cultured cells from human GB tumor. All animal experiments were performed in accordance with the European Communities Council Directive of 22 September 2010 (2010/63/EU) regarding the use of animals in research and were approved by the Ethics Committee of the Institute of Experimental Medicine and Committee of Czech Academy of Sciences.

Formation of tumor in mice. About $1 \times 10^{5}$ cells in $2 \mu \mathrm{l}$ of medium were injected in 5 athymic nude FOXN1nu male mice under anesthesia (isoflurane/oxygen) mounted in a robotic stereotaxic frame (Neurostar, Tübingen, Germany). The cell suspension was injected in the left parietal cortex/corpus callosum using a $10 \mu \mathrm{l}$ Hamilton syringe with a 35G beveled tip needle (World Precision Instruments, Sarasota, FL, USA). The skull hole was then filled with bone wax (B.braun, Melsungen, Germany) and the skin incision was sutured with non-absorbable 6-0 Prolene (Ethicon Inc., Johnson \& Johnson, Somerville, NJ, USA). Tumors developed in mice 1-4. Brains with tumors from mice 1-3 were processed for histology, brain tissue from mice 4 was processed for cell cultures.

Magnetic resonance imaging (MRI). In vivo MRI was performed using a Bruker Biospec 4.7 T MR imager (Bruker BioSpin, Ettlingen, Germany). Mice were scanned at 7, 14, and 21 days and then once per month to monitor tumor formation. The animals were anesthetized by passive inhalation of isoflurane and a routine scanning protocol was used. The scanning protocol included a fast gradient echo localizer for proper positioning, and a T2-weighted 
Turnovcova et al: Tumor-derived Spheroids from Glioblastoma

turbo spin-echo sequence, turbo factor 8 , inter-echo time $\mathrm{TE}=12 \mathrm{~ms}$, effective TE=36 ms, TR=3000 ms, number of acquisitions $\mathrm{NA}=16$, field of view FOV $=20 \times 20 \mathrm{~mm}$, matrix $128 \times 128$, slice thickness 0.5 $\mathrm{mm}$ transversal orientation (scanning time $13 \mathrm{~min}$ ). In situ, postmortem MRI was performed on fixed brains in formaldehyde using a scanner Bruker ICON 1.0 T (Bruker BioSpin). The images were obtained using a T2-weighted turbo spin-echo sequence, turbo factor 16 , inter-echo time TE=14 ms, effective TE=84 ms, TR=6000 $\mathrm{ms}$, the number of acquisitions $\mathrm{NA}=12$, the field of view FOV $=16 \times 16 \mathrm{~mm}$, matrix $128 \times 128$, slice thickness $0.5 \mathrm{~mm}$ transversal orientation (scanning time $6 \mathrm{~h}$ ).

Histology. Routine histological and immunohistochemical (IHC) and immunohistofluorescent techniques were used on formalin-fixed paraffin-embedded sections following the manufacturer's protocol. Human cells were identified by the human-specific mitochondrial marker MTC02 (1:400, Abcam, Cambridge, UK) or Ku80 (1:200, Abcam), tumor cells were positive for Sox 2 and Oct3/4 (ABclonal, Woburn, MA, USA), (1:200 and 1:100 resp.,), nestin (1:200, Millipore Merck, Burlington, MA, USA) and GFAP-CY3, (1:200; Sigma-Aldrich). Alexa Fluor 594 or 488 goat anti-rabbit or antimouse (both Molecular Probes, Eugene, OR, USA) were used as secondary antibodies. Cell nuclei were counterstained with NucBlue (Thermo Fisher Scientific, Waltham, MA, USA). GB primary spheres grown on Matrigel were fixed in warm 4\% PFA prior to staining, Further procedure was the same as for IHC.

Adherent cells in $2 D$ cultures. Immortalized human endothelial cell line hCMEC/D3 (Millipore Merck, Burlington, MA, USA). Briefly, cells were plated on flasks coated with collagen I from rat tail (Sigma Aldrich) in EndoGRO-MV medium (Merck, Darmstadt, Germany) containing penicillin/streptomycin (Gibco, Life Technologies, Grand Island, NY, USA) and Primocin (InvivoGen, San Diego, CA, USA).

GB cell adherent cultures (750000 nucleated cells/well) were seeded onto 6-well dishes coated with collagen I or Matrigel. Cells were grown in endothelial cell growth media - microvascular vessel (EGM-MV) consisting of DMEM/F12, 10\% FBS, endothelial cell growth supplement (ECGS) (Sigma-Aldrich), Primocin, and penicillin/streptomycin.

Primary and secondary spheroids culture. The cell suspension was cultured in a serum-free medium until small spheroids were detectable (Figure 1). The medium consisted of DMEM/F12, 500 $\mathrm{mg} / 100 \mathrm{ml}$ recombinant human albumin from rice (Sigma Aldrich), 1x N2-B, $20 \mathrm{ng} / \mathrm{ml} \mathrm{rhEGF}, 20 \mathrm{ng} / \mathrm{ml} \mathrm{rhFGF}$ (Stemcell Technologies, Vancouver, BC, Canada), $4 \mathrm{ng} / \mathrm{ml} \mathrm{rhIGF}$, heparin, freshly added Glutamine, Primocin, penicillin/streptomycin. 750,000 cells $/ \mathrm{ml}$ media were seeded per well.

Secondary GB spheroids were created in $2 \mathrm{D}$ culture in a sterilized silicone mold (gift from Ita-Intertact, Prague, Czech Republic), consisting of 256 pits filled with sterile melted 2\% agarose (MicroTissues ${ }^{\mathrm{TM}}$, Inc. Providence, RI, USA). Solidified agarose mold was transferred to a 12-well plate and then equilibrated with a culture growth medium. Pre-cultured GB cells (about 200,000) were seeded in agarose. One thousand cell size spheroids were formed in each pit (one spheroid per pit).

FACS analysis of cultured cells. Cells from tumor or xenograft at passage 3 (P3; Figure 1) were harvested using trypsin/EDTA, counted and labeled with appropriate antibodies to anti-human SSEA4, sox2, CD133, CD146, CD73, CD90, CD105, EGFR, EGFRviii, PDGFR-A, PDGFR-B, Oct3/4, A2B5, CD44, CD45, VEGFR2 according to manufacturer's protocols and then analyzed on a BD LSR II flow cytometer. Results were analyzed using FlowLogic $^{\mathrm{TM}}$ Software (Inivai Technologies, Mentone, Victoria, Australia). GB cells isolated from mouse tumor were stained for anti-mouse CD45, anti-human CD45, human HLA-I, A2B5, EGFR, PDGFRB, SSEA4, CD133, CD73, CD90, CD105 to confirm the human origin of tumor cells and assess their phenotype.

Migration assays. Migratory behavior of tumor cells derived from primary (human or mouse brain resections) or secondary spheroids were assessed. Spheroids were seeded into 15 well angiogenic chambers (Ibidi, Gräfelfing, Germany) coated with Matrigel (Corning, New York, USA) or collagen I. Spheroids were left overnight to attach, and live images were taken at $24,48,72$, or 96 $\mathrm{h}$. The number of cells migrated away from the spheroid, the core radius of the spheroid, and the invasive radius of migrating cells were counted and analyzed using ImageJ (U.S. National Institutes of Health, Bethesda, MD, USA).

Chemotactic migration was performed in XCELLigence RTCA DP Instrument (Agilent Technologies Inc., Santa Clara, CA, USA) 16-well cell invasion and migration (CIM) plates. The system monitored cell migration continuously in real-time over the entire time course of the experiment. GB cells $(10,000 /$ well $)$ cultured from human or mouse brain resection were seeded in the upper chamber of CIM plate wells coated with a thick layer of Matrigel or uncoated. Quiescent cells were allowed to migrate towards the serum $(10 \%)$ containing medium added to the lower chamber of selected wells as a chemoattractant. Cells adhering to the microelectrode sensors lead to an increase in impedance, which is measured in real-time by the RTCA DP Instrument (Agilent Technologies Inc.) and expressed as a Cell index. Invasive properties of cells were measured by cell movement through Matrigel and adherence to the microelectrode sensors.

Proliferation assay. Cells from tumor or xenograft were seeded $(100,000 /$ well) in 6-well plates rinsed with Anti-adherence rinsing solution (StemCell Technologies) in serum-free medium as described earlier in the section "GB cell adherent cultures culture" (12). The number of spheres was counted and the size of the spheroids (diameter and area) was measured in Image J after 1, 3 and 7 days from 3 random fields/well.

Angiogenesis assay. Tube formation analysis was performed in a special 96-well angiogenic plate (Ibidi, Gräfelfing, Germany). The tumor cells were grown either in control medium EGM-MV with ECGS or when angiogenesis was induced, the induction medium EGM-2MV contained VEGF $(10 \mathrm{ng} / \mathrm{ml})$ instead of ECGS. The human immortalized microvascular endothelial cell line hCMEC/D3 was used as a positive control and was grown in control EndoGroMVmedium or induction medium EndoGro-MV containing $10 \mathrm{nM}$ VEGF. Cells $(10,000 / 50 \mu \mathrm{l}$ of control or induction media) were seeded onto the Matrigel (GF reduced, Corning) coated wells and the tube formation process was recorded for $18 \mathrm{~h}$ using IncuCyte ${ }^{\circledR}$ ZOOM System (EssenBiosciences, Ann Arbor, MI, USA). The scanning sequence was launched immediately and repeated every $20 \mathrm{~min}$. Angiogenesis Analyzer for ImageJ was used to analyze the experiments as described earlier (17). 


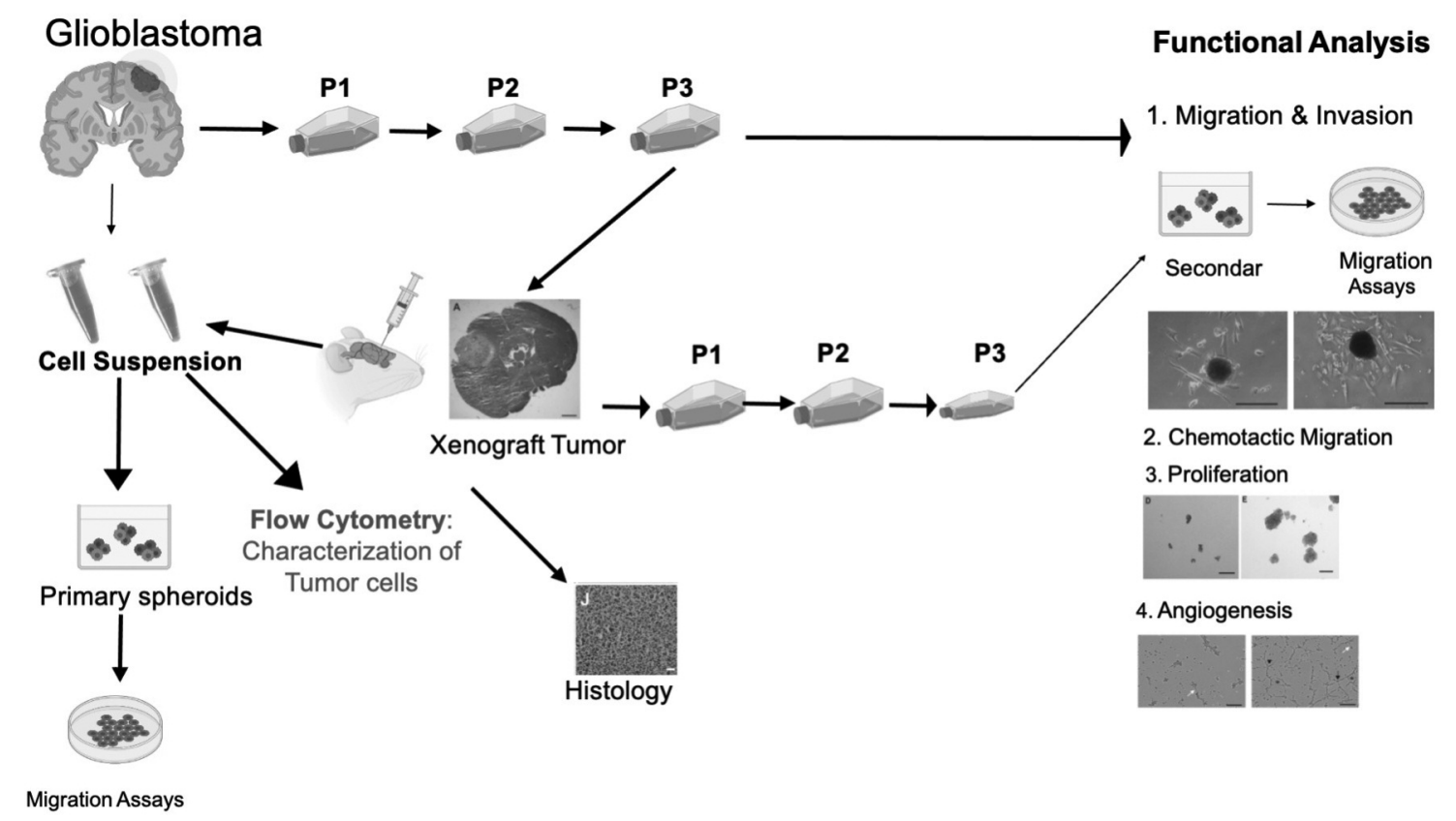

Figure 1. Schematic representation of experimental procedures. Diagram of the algorithm used in experimental procedures to set up tumor formation, in vivo model, extraction of GSC, histology, FACS sorting, and functional analysis performed on $2 D$ and $3 D$ spheroids.

\section{Results}

Tumor growth in an orthotopic mouse model. It has been shown that GSC are capable of forming tumors in a xenograft model (15). To understand the heterogeneity of GSC, the stem cells derived from patient tumors (human GSC) were administered into 5 mice as described above. In Figure 2, two varieties of tumors were formed in this process. One of these tumors formed within 2 weeks of inoculation and had welldefined margins. In mouse 1 , the tumor mass was detected at day 14 with a visible blue/black macula on the epithelium directly overlying the tumor; MRI then confirmed the size and location of the tumor (Figure 2C). The animal brain was histologically examined. On the other hand, MRI from the other 4 mice showed only hypointense signals originating from the blood clot at the inoculation site (Figure 2G). Five months post-inoculation 3 out of these 4 mice started to show enlarged skulls, apathetic behaviors, or balance problems; they were therefore sacrificed. Two animals were trans-cranially perfused with cold PBS followed by 4\% PFA, and brains were histologically analyzed. Tissue from mouse 4 was removed in order to analyze the living cells and to extract xenograft GSC. As shown in Figure $2 \mathrm{H}$, in comparison with the clearly defined tumor described above, a more diffuse tumor with more nebulous margins was revealed by postmortem MRI. These findings were confirmed by a histological analysis which showed a diffuse tumor, without distinct margins (Figure 2F, I and J). While the fast-growing tumor had typical features, such as early signs of pseudopalisading structures (Figure 2D) and microvascularization (Figure 2E), slow-growing tumors spread to both hemispheres as unbounded diffusely growing tumor cell populations. High cellularity with high variability in nuclear morphology was noticeable. In addition, high mitotic activity, with occasional atypical mitotic figures were observed. Focally, we also found ischemic necrosis, however, necrosis with palisading was not detected. In order to confirm that these xenograft GSC were of human origin, coimmunostaining of the tumor sections was performed to detect the expression of Ku80 with nestin (Figure $2 \mathrm{~K}$ ) or Ku80 with GFAP (Figure 2L), and observed that xenograft tumors displayed Ku80 expression confirming that these tumors are of human origin. Some of the Ku80 expressing cells also immuostained with stem cell maker nestin (Figure 2K), while only a few were GFAP positive and the majority of GFAP signal was of mouse origin, since it did not co-localize with Ku80 (Figure 2L). We further stained brain slices with stem cell markers, Sox2, and Oct3/4, which showed more Sox2 positive cells (red, M) and fewer Oct3/4 positive cells (red, N). Cell nuclei were counterstained with Nucleus Blue.

Characterization of tumor stem cell phenotypes. Table I shows characteristic tumor cell markers present in human GSC after Passage 3 (P3; Figure 1), xenograft GSC in suspension and xenograft GSC in 2D culture (Figure 3). As shown, human GSC, xenograft GSC, and xenograft GSC in cell culture display multiple stem cell markers, such as SSEA4, Sox2, and 
Table I. Characterization of tumor stem cell phenotypes.

\begin{tabular}{lccc}
\hline Marker & $\begin{array}{c}\text { Human GSC } \\
\text { (P3; collagen } \\
\text { coating) }\end{array}$ & $\begin{array}{c}\text { Xenograft } \\
\text { GSC }\end{array}$ & $\begin{array}{c}\text { Xenograft GSC } \\
\text { (2D culture) }\end{array}$ \\
\hline SSEA4 & + & + & +++ \\
Sox2 & ++ & ++ & + \\
Oct4 & + & - & + \\
CD133 (Prominin-1) & - & - & - \\
CD44 & +++ & - & - \\
CD45 & - & ++ & - \\
CD73 & +++ & - & - \\
CD90 (Thy-1) & +++ & +++ & - \\
CD105 (Endoglin) & +++ & ++ \\
CD146 & ++ & - & - \\
A2B5 & - & - & + \\
VEGFR2 & - & & - \\
EGFR & +++ & ++ & - \\
EGFRviii & - & ++ & \\
PDGFR-A & - & & \\
PDGFR-B & +++ & & \\
Human cells & & & \\
(HLA-I positive) & & & \\
\hline
\end{tabular}

$-=1-10 \% ;+=10-40 \% ;++=40-70 \% ;+++=70-100 \%$ cell positivity; Blank cells: not evaluated.

Oct3/4. Analysis of cell surface markers revealed that these cells were $\mathrm{CD}_{133^{-}}$, however strong positivity for CD90 was observed in human GSC and xenograft GSC, which was lost in 2D cultured xenograft GSC. Other cell surface markers, CD73, CD105, and CD146 were present at high levels in human GSC, but not in xenograft GSC and xenograft GSC in 2D culture. CD44 positive cells were observed in human GSC as well as xenograft GSC in 2D culture in large numbers.

As shown in Table I, human and xenograft GSC as well as xenograft GSC from 2D culture were all negative for PDGFR $\alpha$ expression. However, the expression of PDGFR $\beta$ was only seen in human and xenograft cells grown in $2 \mathrm{D}$ culture. Human and xenograft GSC as well as xenograft GSC from 2D culture were positive for EGFR, however, the EGFRviii mutant variant was absent in all groups, which suggests that these tumors were all EGFR wildtype.

Migration capability of tumors. In order to examine the aggressive behavior of cells in spheroids, we performed cell migration analysis using random, directional, and chemotactic techniques. Our results demonstrated that primary human spheroid cells migrated better on the collagen matrix compared to Matrigel matrix (Figure 3A and B). In contrast, the primary xenograft spheroid had robust migration on Matrigel matrix, but migrated poorly on the collagen matrix (Figure 3C and D). In order to confirm the stemness of primary spheroids, we stained xenograft GSC with Oct3/4 and Sox 2 as presented in Figures $3 \mathrm{E}$ and $\mathrm{F}$. Further analysis of migration was performed on secondary spheroids, which were prepared from the 2D culture (P3) along with human GSC (Figure $3 \mathrm{G}$ and $\mathrm{H}$ ), or xenograft GSC (Figure 3I). We evaluated the spheroid size and migration around it as a ratio of spheroid diameter and invasive radius (distance of migration) as shown in Figure 3J. The results demonstrate that the secondary spheroids had the largest invasive radius and their migration was more dispersed as compared to primary human spheroids and primary xenograft spheroids as described in Figures 3G, H, and I. However, when we evaluated migration as a ratio of the number and distance of migrating cells from the spheroid core, the primary xenograft spheroids exhibited the most robust migration, which was significantly higher than that of the primary human spheroids (Figure $3 \mathrm{~K}$ ). The primary human spheroids also migrated significantly compared to the secondary human spheroid (Figure $3 \mathrm{~K})$. It is important to mention that secondary spheroid migration was noticeably lower when measured by cell distance from the spheroid core. Secondary human spheroids migrated well on both Collagen as well as on Matrigel (Figure 4A), however, migration was significantly greater on Matrigel (Figure 4A, B, and C). Secondary xenograft spheroids migrated faster than secondary human spheroids (Figure 4D).

Real-time chemotactic migration towards $10 \%$ FBS was recorded using the XCelligence apparatus over the course of $24 \mathrm{~h}$. Timed chemotactic migration of human GSC was compared with xenograft GSC, which demonstrated that the migration rate of the xenograft GSC was significantly greater than the human GSC (Figure 4E). The migration rate was expressed as changes in cell index.

We also studied the invasion of these cells which are expressed in Figure 4F. As seen with migration, the xenograft GSC (grey line) were also found to be highly invasive relative to the human GSC (black line).

Proliferation of GSC. We evaluated the proliferation of human GSC as well as xenograft GSC. Both types of GSC formed a similar number of neurospheres in $24 \mathrm{~h}$. However, we observed that over the course of seven days, the size of the neurospheres derived from human GSC was significantly enlarged compared to that from xenograft GSC (Figure 5A). This includes the diameter and area of the spheres (Figure $5 \mathrm{~B})$. These results suggest that the size of the neurospheres formed from human GSC was larger compared to that from xenograft GSC (Figure 5C and D).

Angiogenic potential of these tumors. Angiogenic sprouting from individual beads was evaluated by phase-contrast microscopy allowing for quantification of in vitro angiogenesis in an Endothelial basal medium containing VEGF (labeled "Induction") and a growth medium ("Control"), as described in detail in the methods section. As shown in Figure 6A, human GSC demonstrated the ability to form tube-like structures that consist of nodes, meshes, junctions, and 

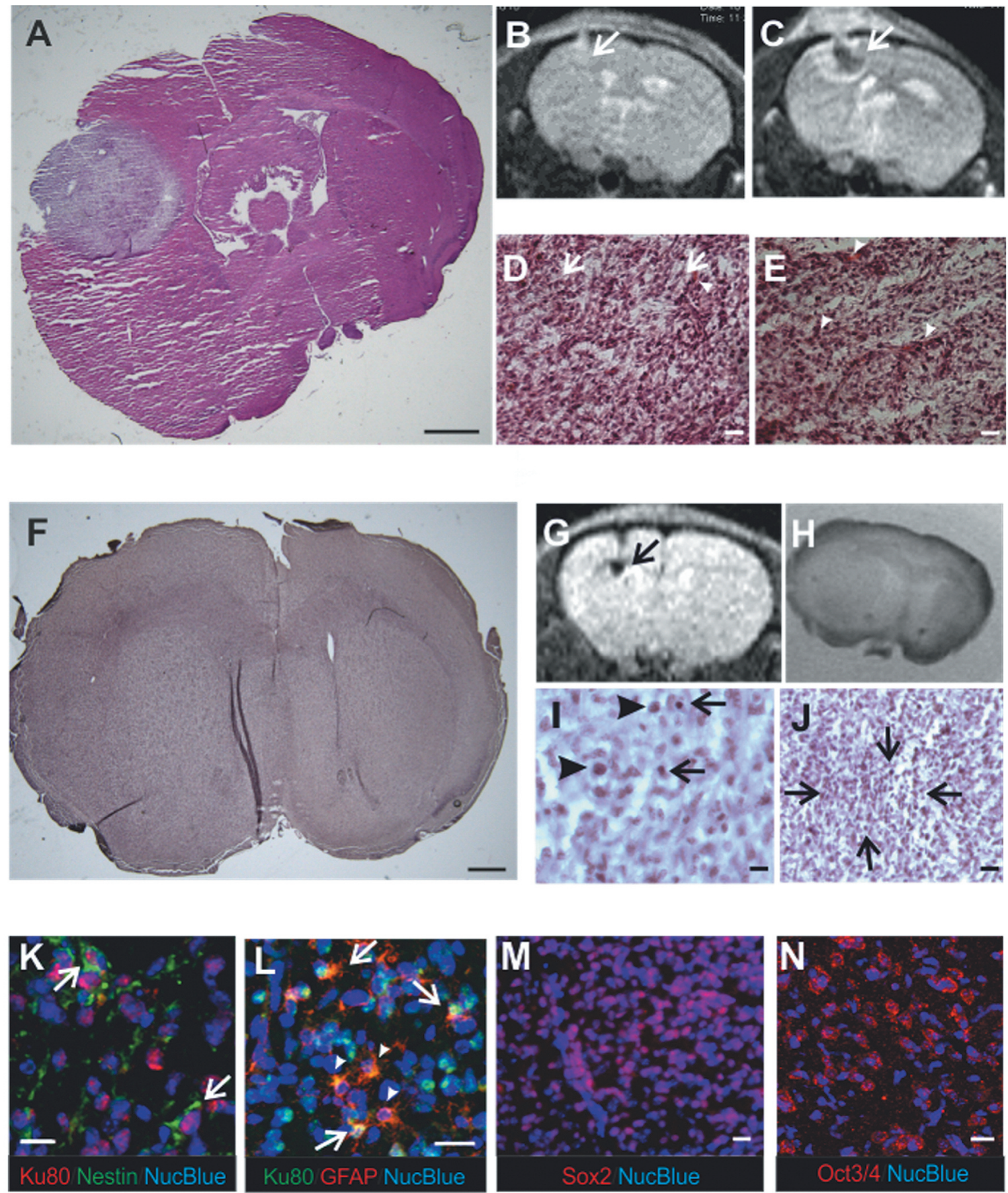

Figure 2. Tumor growth in an orthotopic mouse model. A total of 100,000 human GSC in PBS were injected into the left parietal cortex of 5 mice $(A, F)$. The injection site (arrow) was visible one week after inoculation on T2W images (B). A tumor (arrow) was detected in mouse 1 by MRI at 2 weeks after injection, $(C)$. The other 4 mice did not show any signs of tumor formation, only a hypointense signal from the blood clot was detected at the injection site, the arrow $(G)$. The tumor in mouse 1 was clearly delineated (A) showing typical GB features, including early signs of pseudopalisading (arrows), and microvascularization (arrowheads) $(D, E)$. Tumors in mice 2-4 developed in the next 5 months, showing diffuse spread with irregular borders $(F)$. Histology $(F)$ and MRI $(H)$ showed enlargement exclusively in the left hemisphere. High cellularity with high variability of nuclear morphology (arrowheads) and high mitotic activity (arrows) is noticeable (I), focally ischemic necrosis (arrows) is observed(J). Tumor cells were Ku80 positive (red) and displayed an indication of dedifferentiation, as these cells were nestin-positive (green, arrows) (K). A small fraction of cells was GFAP positive (arrow) among the Ku80 positive tumor cells (green, Ku80) while the remaining GFAP (red) positive cells (arrowheads) were of mouse origin $(L)$. The tumor was strongly positive for Sox 2 (red, M) and Oct3/4 (red, N). Cell nuclei were counterstained with Nucleus Blue. Scale bars A, F=1 mm; B, C, D, E, G, H, I, J, K, L, M, N=20 $\mu \mathrm{m}$. 


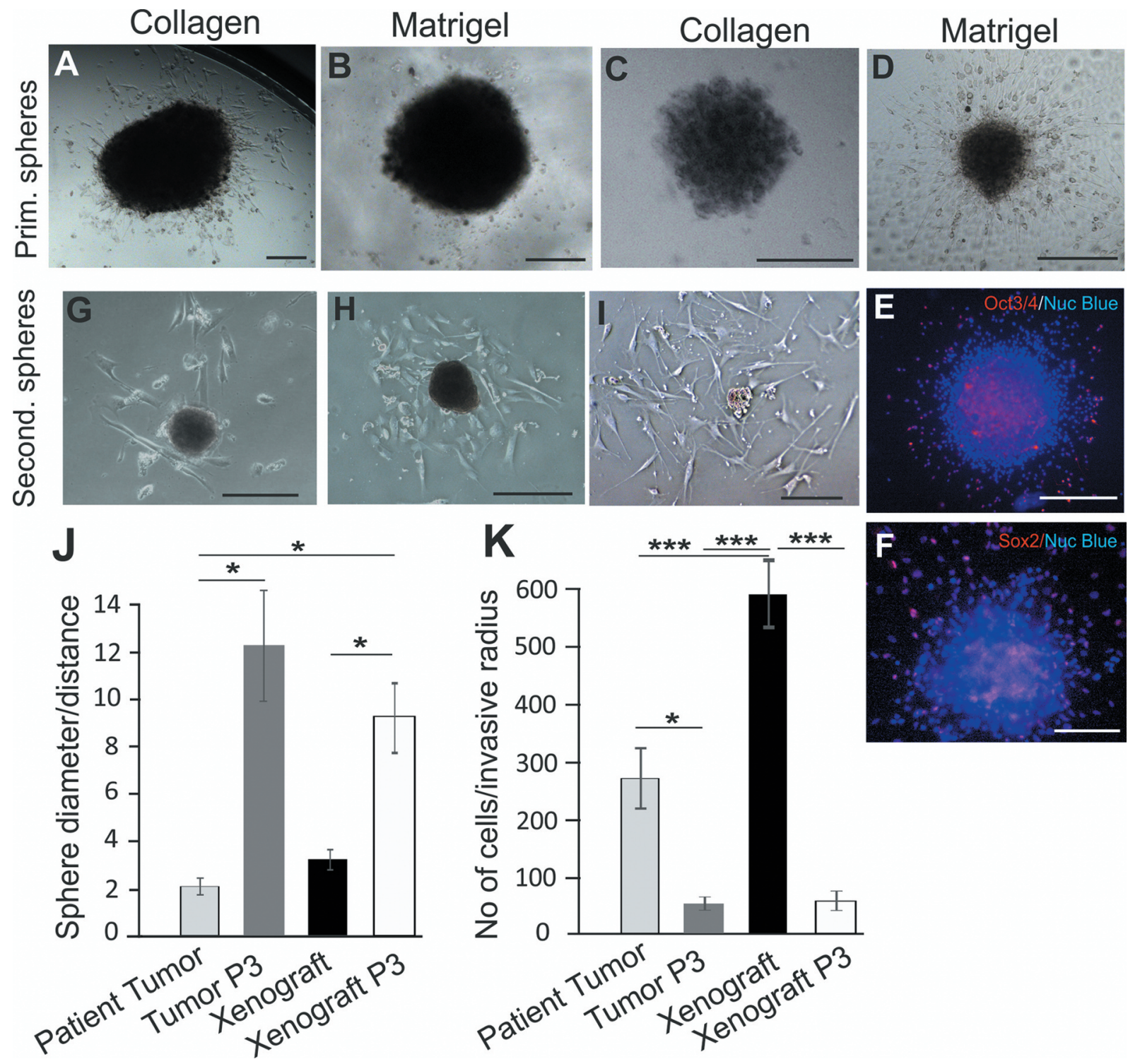

Figure 3. Directional or random cell migration of spheroids. Cell migration of primary human spheroids $(A, B)$ and primary xenograft spheroids $(C, D)$, was performed in serum-free medium and seeded on collagen $(A, C)$ or Matrigel $(B, D)$. Primary human spheroids migrated on collagen $(A)$, but not on Matrigel (B). Conversely, the primary xenograft spheroids robustly migrated on Matrigel $(D)$, but not on collagen $(C)$. Primary xenograft spheroids were positive for Oct3/4 (E) and Sox2 (F). Secondary spheroids were prepared from $2 D$ culture (Passage 3) from human GSC $(G, H)$, or xenograft GSC (I). These secondary spheroids migrated on both coatings. Migration with respect to spheroid size was evaluated as a ratio of core radius/invasive radius $(J)$. The secondary spheroids had larger invasive radius $(J)$ and their migration was more dispersed $(G, H, I)$. Evaluation of migration as a ratio of the number of migrating cells/invasive radius showed that the most robust migration was seen from primary xenograft spheroids $(K)$. These cells migrated radially $(D)$. Scale bars A-E=200 mm, F=100 $\mathrm{mm}$.

branches even in the control medium without VEGF. Vessel formation can be analyzed in real-time using time-lapse imaging analysis (Figure 6B), which clearly depicts the number of meshes, nodes, junctions, and branches. In comparison, we also used a human endothelial cell line (hCMEC) which only produced angiogenic elements in the induction medium.
Regarding human GSC, we noted that these cells were able to produce tube- and branch-like structures as shown in Figure $6 \mathrm{~B}$, however, this process was enhanced in the "induction" medium containing VEGF. After $18 \mathrm{~h}$ of treatment, while nodes and branches increased significantly in human GSC, junctions only showed a trend towards increase, and mesh 

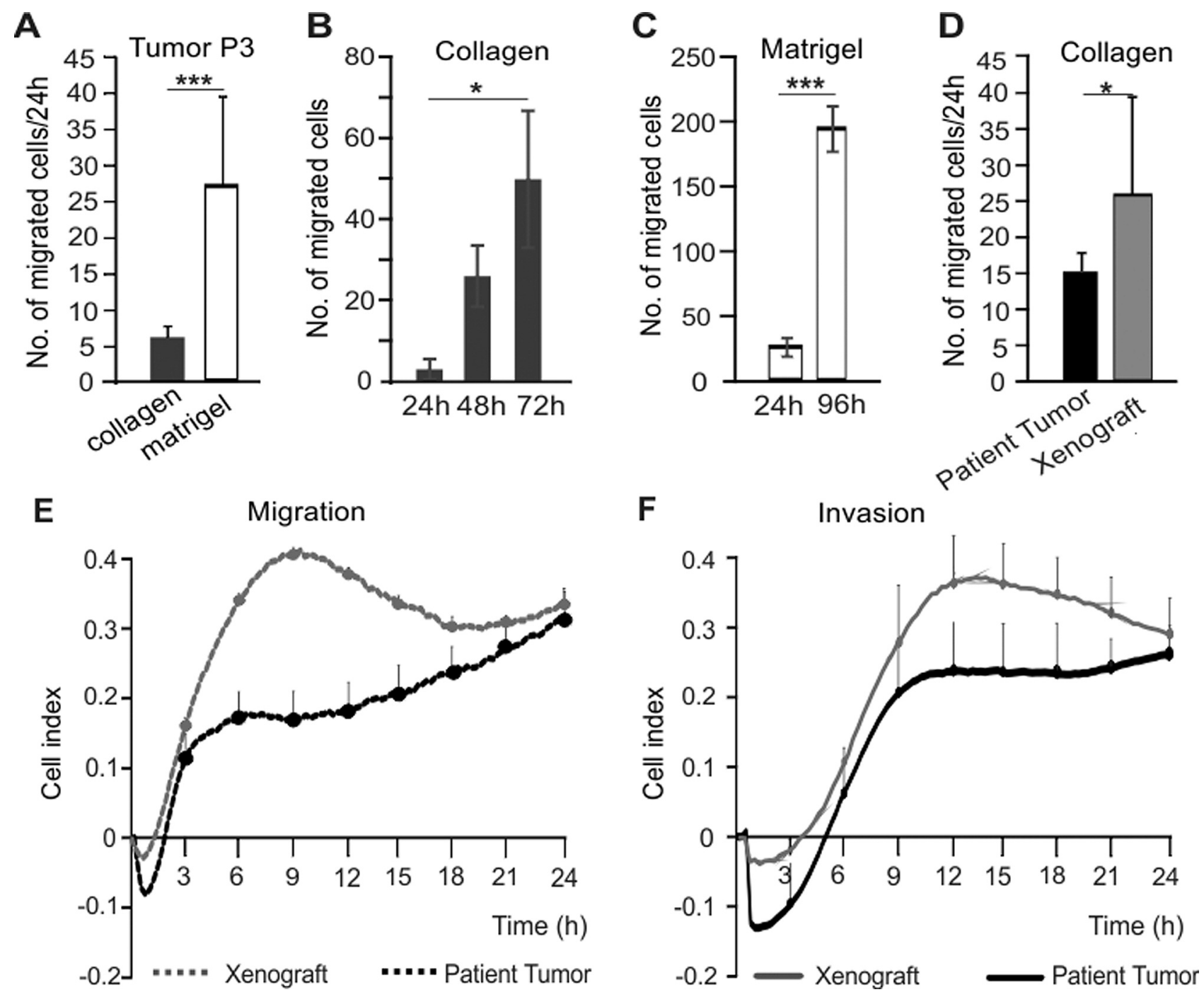

Figure 4. Cell migration properties of human GSC and xenograft GSC. Dispersed migration was assessed in secondary spheroids (Passage 3). Human GSC migrated on collagen (A, B) and xenograft GSC migrated on Matrigel (C). Xenograft GSC migrated robustly on Matrigel (A, C). When the migration of the secondary human spheroids was compared with the secondary xenograft spheroids on collagen, the latter of the two migrated more robustly (D). Chemotactic migration of human GSC was compared to that of xenograft GSC (E). Cells migrated from the upper chamber containing 0\% FBS to the lower chamber containing 10\% FBS on CIM-plates. The migration rate was expressed as changes in cell index over 24 h. Xenograft GSC (dotted grey line) migrated faster than the human GSC (dotted black line). Solid lines show invasion through a thick drop of Matrigel from the upper chamber to the bottom chamber $(F)$. The invasion rate was expressed as changes in cell index after 24 h. As shown here, xenograft GSC (grey line) migrated faster through the Matrigel than the human GSC (black line).

formation showed only marginal changes. As shown in Figure 6B, hCMEC showed a pronounced increase in nodes, branches, junctions, and meshes following induction with VEGF only.

\section{Discussion}

Glioblastoma and its GSC are characterized by extensive intratumoral heterogeneity that is displayed in their biological properties and may drive resistance to the current therapies
(18). These untreatable GSC appear to be unique in maintaining their stemness even in complex microenvironment niches. Understanding GSC behavior could shed light on tumor recurrence, dissemination, and resistance to therapies. The results of this study demonstrate that stem cells generated from patient tumors can produce distinct xenograft tumors. The human-derived GSC had a slower migratory rate as compared to their xenograft GSC. On the other hand, human GSC displayed increased proliferation compared to their 

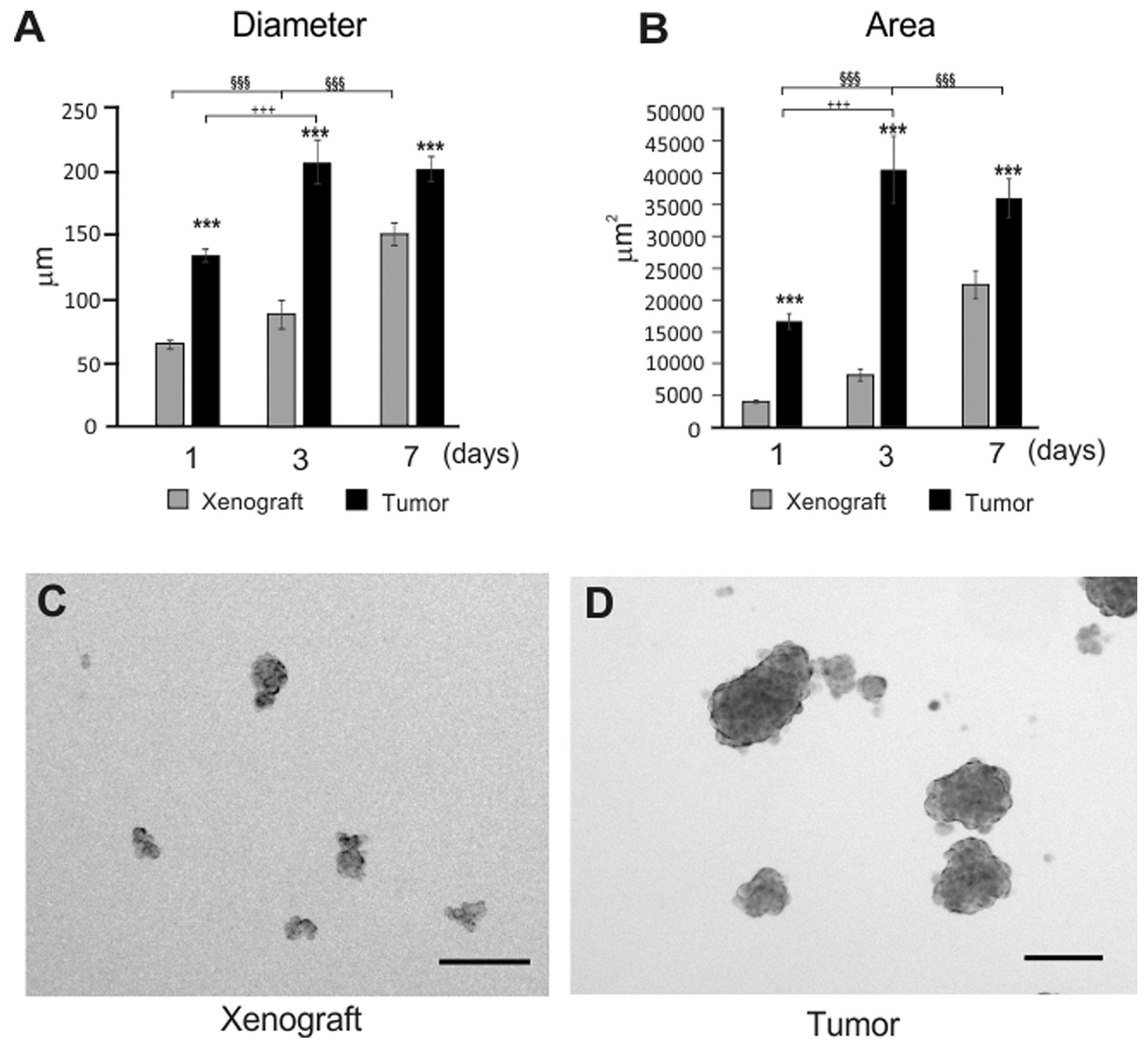

Figure 5. Proliferation of GSC. A total of 100,000 cells from human GSC or xenograft GSC were seeded in 6-well plates and rinsed with antiadherence rinsing solution. Measurement of diameter $(A)$ and area $(B)$ of spheres were followed over a course of 7 days. The size of neurospheres formed in 24 h from xenograft GSC (C) was noticeably smaller than that of those formed from human GSC (D). Scale bar $200 \mu \mathrm{m}$.

xenograft GSC. Human GSC were also found to be capable of inducing angiogenesis in the absence of VEGF.

Several studies have shown that GSC are present in GB as well as in other brain tumors (14-16). These studies have shown that $\mathrm{CD} 133^{+} \mathrm{GSC}$ form tumors of parental origin when grafted in NOD-SCID (non-obese diabetic, severe combined immunodeficient) mouse brains. Furthermore, these stem cells showed properties like neurosphere-forming capacity, selfrenewal, high proliferative potential, and multipotency (19). In addition, the xenograft tumors had histopathological features identical to those of the original GB tumor (19). Several studies have provided evidence that enrichment of GSC in $\mathrm{CD} 133^{+}$ cells is observed after irradiation in both xenograft tumors and neurosphere cultures, showing a reduction in apoptosis and the phosphorylation of histone H2AX (20). These observations strengthen the view that this resistance to therapy may be due to such a mechanism. In addition, it has been shown that $\mathrm{CD}_{133^{+}}$cells isolated from primary cultured cells from GB tumors displayed increased resistance to chemotherapeutic agents compared with $\mathrm{CD} 133^{-}$stem cells (21). Similar to results previously shown in leukemia (22), human GB may demonstrate resistance to therapy because of stem cell resistance. The hypothesis that only $\mathrm{CD} 133^{+}$cells, but not $\mathrm{CD}_{133^{-}}$cells, possess stem cell properties and are capable of 
A

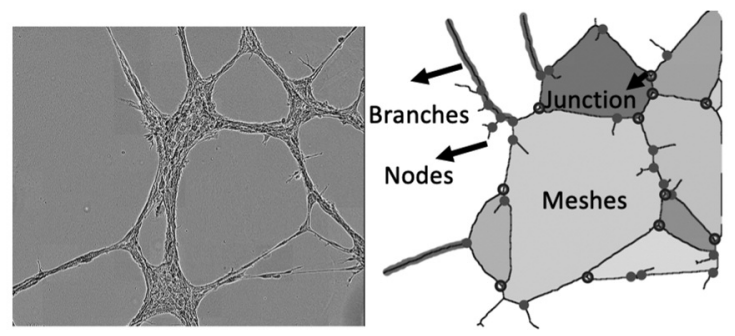

B

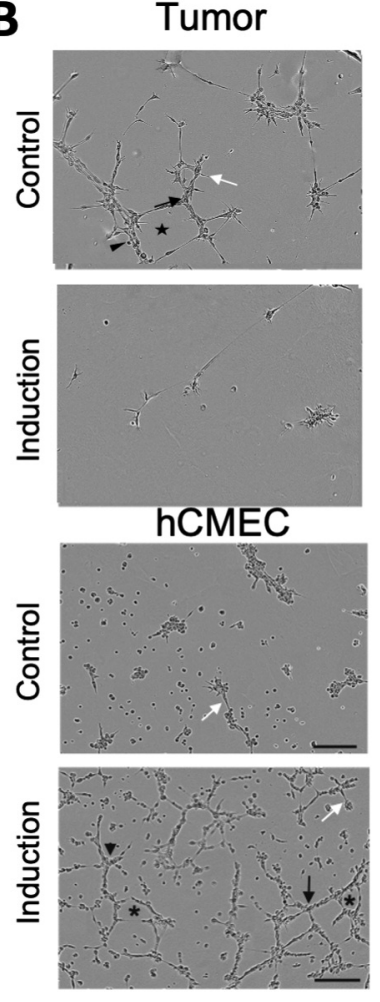

C
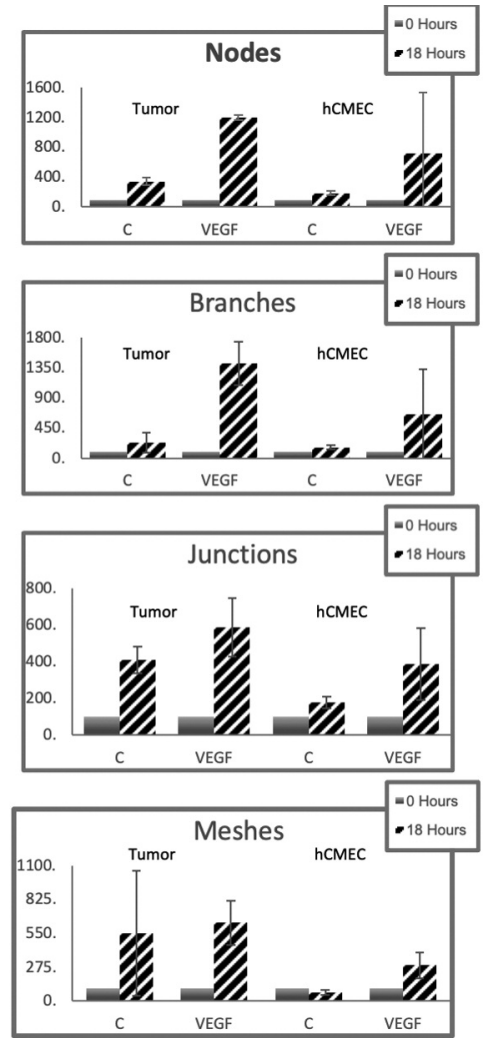

Figure 6. Angiogenesis in-vitro. (A) Formation of tube-like structures, includes nodes, meshes, junctions, and branches as part of angiogenesis. (B) Human GSC showed the ability to form tube-like structures (nodes, meshes, junctions, and branches) even in the maintenance (control) medium in the absence of VEGF and following induction with VEGF. (C) Quantification of in vitro angiogenesis in Endothelial basal medium 2 ("Induction") with VEGF and control growth medium ("Control"). Additionally, this occurred while the human endothelial cell line ( $h C M E C)$ produced angiogenic elements only in the induction medium. Example of in vitro angiogenesis in control and induction medium. White arrows=branches, black arrows=junctions, asterisk=meshes, black arrowhead=nodes. Scale bar $=300 \mu \mathrm{m}$.

forming tumors is highly controversial since both $\mathrm{CD} 133^{+}$and $\mathrm{CD}_{133^{-}}$cells were found to be tumorigenic in experimental models (23). In fact, CD133- cells have been shown to possess tumor-initiating properties (24). In addition, these investigators have found that cells derived from GB tumors that exhibited stem-cell-like properties were CD133- (24). This observation is in line with our finding of absence of $\mathrm{CD} 133^{+}$cells in our human or xenograft GSC. Hence, it could be concluded that both $\mathrm{CD}_{133^{+}}$as well as $\mathrm{CD} 133^{-}$GSC are capable of forming multipotent spheres, which have all the properties of stem-cells including self-renewal, proliferation, and differentiation (25). In our study, we showed that both tumor and xenograft GSC were $\mathrm{CD}_{133^{-}}$, but they were positive for stem cell markers such as Sox2 and Oct3/4.

Diffuse invasion of tumor cells within the surrounding brain parenchyma is a key characteristic of GB that renders complete surgical resection impossible (2). Recent investigation has shown that high $\mathrm{CD}^{+} 0^{+}$cells in $\mathrm{GB}$ display a more invasive phenotype relative to low $\mathrm{CD}^{+} 0^{+}$cells (26).
Our observation corroborates with this study as we show higher levels of CD90 ${ }^{+}$cells in human GSC, xenograft GSC, and xenograft GSC in culture (Table I).

The spheroids developed from human or xenograft tumor, both provide molecular and cellular analyses of enriched GB stem-cell populations to reveal a variety of aspects of their metabolism and in vitro and in vivo cellular properties. In fact, resulting spheroids, comprised of GSC, are used to study in vitro growth properties, chemoresistance, epigenetic characteristics, and tumor-initiating potential. Such GSC have also been utilized successfully to perform drug screening for small molecule compounds that may target these unique tumor cells $(27,28)$. Other approaches to enrich GSC use antibodymediated selection for putative GSC-specific epitopes, such as the $\mathrm{CD}_{133^{+}}$population of GB cells, through panning or fluorescence-activated sorting (29-31). Our studies showed A2B5+ cells were present in xenograft GSC and xenograft GSC from 2D culture but were absent in human GSC populations. A2B5 is a cell surface ganglioside that exists in 
glial precursor cells and found in glioma-initiating cells. Several studies have demonstrated that $\mathrm{A} 2 \mathrm{~B}^{+}$cells are capable of forming tumors in immunocompromised mice and A2B5 cells are void of this ability $(32,33)$. A2B5 expression is also associated with $\mathrm{CD}_{133^{+}}$expression. It is important to note, in our study, we observed a stem cell population that was $\mathrm{CD}_{133^{-}}$. Consistent with our findings, it has been shown by others that $\mathrm{A} 2 \mathrm{~B} 5$ is present in $\mathrm{CD} 133^{-}$cells which nevertheless express stem cell properties, implying that A2B5 is an important marker of stem cell quality (34). In addition, $\mathrm{CD} 133^{-} / \mathrm{A} 2 \mathrm{~B}^{+}$cells exhibit neural stem-like cell properties, and the $\mathrm{CD} 133^{-} / \mathrm{A} 2 \mathrm{~B} 5^{+}$cell population that displays excessive migratory and invasive potential can be associated with GB tumor recurrence despite conventional therapies. Moreover, only $\mathrm{A} 2 \mathrm{~B} 5^{+} / \mathrm{CD}_{133^{+}}$and $\mathrm{A} 2 \mathrm{~B} 5^{+} / \mathrm{CD} 133^{-}$but not $\mathrm{A} 2 \mathrm{~B}^{-} / \mathrm{CD} 133^{-}$cell populations from $\mathrm{GB}$ were capable of forming neurospheres in vitro and initiating the formation of tumors in vivo, signifying that A2B5 is an important marker of GSC $(32,35)$.

Typical mesenchymal markers, CD73, CD90, and CD105, were present in $2 \mathrm{D}$ tumor culture, suggesting GSC have a mesenchymal phenotype (36). It is important to note that xenograft GSC may dedifferentiate and show positivity only for SSEA4, which is a typical human embryonic marker (37). Since SSEA4 positivity was identified as a distinct cell population even from the xenograft tumors, we can deduce that this distinct cell population might be responsible for the generation of clones of daughter cells producing highly SSEA4 positive stem cells. It is important to mention that GB is comprised of 4 genetically defined subtypes, where each is associated with distinct genetic alterations. For example, amplification of PDGFR $\alpha$ in a proneural subtype or loss of tumor suppressor NF1 in mesenchymal subtype, however, it is still uncertain whether these subtypes are different tumors or whether they may have evolved from one another. In fact, it has been shown that these discrete subtypes coexist in some tumors implying a shift between the subtypes (38). On the other hand, it has been reported that upon recurrence, GB tumor characteristics can progress towards the mesenchymal subtype, suggestive of EMT towards a more malignant phenotype (39). Furthermore, studies have revealed the presence of CD90 and CD29 positive cells in most GB, while lacking the expression of CD24 and CD195 (Table I). However, it is important to mention that intra-tumoral heterogeneity of the cell markers CD133, CD44, CD15, and A2B5 have been reported in GB, as could be expected for genuine GSC markers (40). It is possible that the tumor cells alter the expression of some of these markers following the clonal selection, which may reflect the adaptation to a novel microenvironment. Furthermore, we showed that certain cell surface markers and receptors, such as CD106, CD44, CD73, CD146, PDGFR $\beta$, and others were present in the primary human spheroids but not evident in primary xenograft spheroids or xenograft GSC. Such occurrences have also been shown by others (41-43), where some of these cell surface markers showed variable expression under different microenvironments.

It is an intrinsic property of GSC that they are very migratory. Our findings show that the migration ability of human GSC was much lower than their xenograft GSC as shown in Figure 3. Our findings suggest that both human and xenograft GSC were migratory, however xenograft GSC were more migratory (Figure 3). Similar to the migration, the invasion was more pronounced in xenograft GSC (Figure 4). Human GSC proliferated with time, and their proliferative rate was noticeably higher than xenograft GSC (Figure 5). These observations were similar to what we had previously observed, showing that GSC are highly proliferative (44). On the other hand, when we analyzed the functional aspects of these neurospheres, we found that the primary human spheroids were far more aggressive in growth in comparison to their primary xenograft spheroids.

It is important to note that the shift from migration to proliferation is inverted in these two groups, which could be interpreted as an inversion of metabolism. While the human GSC group's energy is utilized for growth proliferation as in the case of the primary human spheroids, the xenograft GSC groups were channeled towards the invasion and migration. Taken together, we found that human GSC were more aggressive regarding growth and proliferation than xenograft GSC, while xenograft GSC had increased invasion and migration compared to human GSC, and both had the capacity for enhanced angiogenesis. Therefore, a simple in vitro system for tumor-derived spheroids provides an excellent platform for the development of precision medicine in GB.

\section{Conflicts of Interest}

All Authors declare no competing financial interests in relation to this study.

\section{Authors' Contributions}

P.J., MJ, contributed to the concept, design development and writing; K.T., DM methodology and execution of experiments; TS Figure, writing \& editing. MK pathology: R.G., Editing \& Figure; V.K., Editing, P.K., R.K., V.H., D.N. Resources. All Authors read and approved the final draft of the manuscript.

\section{Acknowledgements}

The work was supported from the Czech Science Foundation (No. 1704918S) and, by Operational Programme Research, Development and Education in the framework of the project "Center of Reconstructive Neuroscience", registration number CZ.02.1.01/0.0./0.0/15_003/ 0000419. MR Imaging methods were supported by the Ministry of Education, Youth and Sports of the Czech Republic (Large RI Project LM2018129 Czech-BioImaging) and by European Regional Development Fund (Project No. CZ.02.1.01/0.0/0.0/16_013/0001775) Advanced Research Foundation (MJU). 


\section{References}

1 Ostrom QT, Cioffi G, Gittleman H, Patil N, Waite K, Kruchko $\mathrm{C}$ and Barnholtz-Sloan JS: Cbtrus statistical report: Primary brain and other central nervous system tumors diagnosed in the united states in 2012-2016. Neuro-Oncology 21(Suppl_5): v1v100, 2019. PMID: 31675094. DOI: 10.1093/neuonc/noz150

2 Louis DN, Perry A, Reifenberger G, von Deimling A, FigarellaBranger D, Cavenee WK, Ohgaki H, Wiestler OD, Kleihues P and Ellison DW: The 2016 world health organization classification of tumors of the central nervous system: A summary. Acta Neuropathol 131(6): 803-820, 2016. PMID: 27157931. DOI: $10.1007 / \mathrm{s} 00401-016-1545-1$

3 Lim DA, Cha S, Mayo MC, Chen M-H, Keles E, Vandenberg S and Berger MS: Relationship of glioblastoma multiforme to neural stem cell regions predicts invasive and multifocal tumor phenotype. NeuroOncology 9(4): 424-429, 2007. PMID: 17622647. DOI: $10.1215 / 15228517-2007-023$

4 Ohgaki $\mathrm{H}$ and Kleihues P: The definition of primary and secondary glioblastoma. Clin Cancer Res 19(4): 764-772, 2013. PMID: 23209033. DOI: 10.1158/1078-0432.ccr-12-3002

5 Ohgaki $\mathrm{H}$ and Kleihues P: Genetic pathways to primary and secondary glioblastoma. Am J Pathol 170(5): 1445-1453, 2007. PMID: 17456751. DOI: 10.2353/ajpath.2007.070011

6 Parsons DW, Jones S, Zhang X, Lin JCH, Leary RJ, Angenendt P, Mankoo P, Carter H, Siu IM, Gallia GL, Olivi A, McLendon R, Rasheed BA, Keir S, Nikolskaya T, Nikolsky Y, Busam DA, Tekleab H, Diaz LA, Hartigan J, Smith DR, Strausberg RL, Marie SKN, Shinjo SMO, Yan H, Riggins GJ, Bigner DD, Karchin R, Papadopoulos N, Parmigiani G, Vogelstein B, Velculescu VE and Kinzler KW: An integrated genomic analysis of human glioblastoma multiforme. Science 321(5897): 18071812, 2008. PMID: 18772396. DOI: 10.1126/science.1164382

7 Network TCGAR: Comprehensive genomic characterization defines human glioblastoma genes and core pathways. Nature 455(7216): 1061-1068, 2008. PMID: 18772890. DOI: 10.1038/ nature 07385

8 Mangiola A, Lama G, Giannitelli C, De Bonis P, Anile C, Lauriola L, La Torre G, Sabatino G, Maira G, Jhanwar-Uniyal M and Sica $\mathrm{G}$ : Stem cell marker nestin and c-jun nh2-terminal kinases in tumor and peritumor areas of glioblastoma multiforme: Possible prognostic implications. Clin Cancer Res 13(23): 6970-6977, 2007. PMID: 18056172. DOI: 10.1158/1078-0432.ccr-07-1229

9 Jhanwar-Uniyal M LM, Friedman M, Kwasnicki A and Murali R: Glioblastoma: Molecular pathways, stem cells and therapeutic targets. Cancers (Basel) 7(2): 538-555, 2015. PMID: 25815458. DOI: $10.3390 /$ cancers 7020538

10 D'Alessio A PG, Sica G and Scicchitano BM: Pathological and molecular features of glioblastoma and its peritumoral tissue. Cancers (Basel) 11(4): 469, 2019. PMID: 30987226. DOI: 10.3390/cancers 11040469

11 Ohgaki $\mathrm{H}$ and Kleihues P: Genetic alterations and signaling pathways in the evolution of gliomas. Cancer Sci 100(12): 22352241, 2009. PMID: 19737147. DOI: 10.1111/j.1349-7006. 2009.01308.x

12 Couturier CP, Ayyadhury S, Le PU, Nadaf J, Monlong J, Riva G, Allache R, Baig S, Yan X, Bourgey M, Lee C, Wang YCD, Wee Yong V, Guiot M-C, Najafabadi H, Misic B, Antel J, Bourque G, Ragoussis $\mathrm{J}$ and Petrecca K: Single-cell rna-seq reveals that glioblastoma recapitulates a normal neurodevelopmental hierarchy.
Nat Commun 11(1): 3406, 2020. PMID: 32641768. DOI: 10.1038/s41467-020-17186-5

13 Ignatova TN, Kukekov VG, Laywell ED, Suslov ON, Vrionis FD and Steindler DA: Human cortical glial tumors contain neural stem-like cells expressing astroglial and neuronal markers in vitro. Glia 39(3): 193-206, 2002. PMID: 12203386. DOI: 10.1002/glia.10094

14 Singh SK CI, Terasaki M, Bonn VE, Hawkins C, Squire J and Dirks PB: Identification of a cancer stem cell in human brain tumors. Cancer Res 63(18): 5821-5828, 2003. PMID: 14522905.

15 Hemmati HD, Nakano I, Lazareff JA, Masterman-Smith M, Geschwind DH, Bronner-Fraser M and Kornblum HI: Cancerous stem cells can arise from pediatric brain tumors. Proc Natl Acad Sci USA 100(25): 15178-15183, 2003. PMID: 14645703. DOI: 10.1073/pnas.2036535100

16 Galli R, Binda E, Orfanelli U, Cipelletti B, Gritti A, De Vitis S, Fiocco R, Foroni C, Dimeco F and Vescovi A: Isolation and characterization of tumorigenic, stem-like neural precursors from human glioblastoma. Cancer Res 64(19): 7011-7021, 2004. PMID: 15466194. DOI: 10.1158/0008-5472.can-04-1364

17 Carpentier G, Berndt S, Ferratge S, Rasband W, Cuendet M, Uzan G and Albanese P: Angiogenesis analyzer for imagej - a comparative morphometric analysis of "endothelial tube formation assay" and "fibrin bead assay". Sci Rep 10(1): 11568, 2020. PMID: 32665552. DOI: 10.1038/s41598-020-67289-8

18 Prager BC, Bhargava S, Mahadev V, Hubert CG and Rich JN: Glioblastoma stem cells: Driving resilience through chaos. Trends Cancer 6(3): 223-235, 2020. PMID: 32101725. DOI: $10.1016 /$ j.trecan.2020.01.009

19 Singh SK, Hawkins C, Clarke ID, Squire JA, Bayani J, Hide T, Henkelman RM, Cusimano MD and Dirks PB: Identification of human brain tumour initiating cells. Nature 432(7015): 396-401, 2004. PMID: 15549107. DOI: 10.1038/nature03128

20 Bao S, Wu Q, McLendon RE, Hao Y, Shi Q, Hjelmeland AB, Dewhirst MW, Bigner DD and Rich JN: Glioma stem cells promote radioresistance by preferential activation of the DNA damage response. Nature 444(7120): 756-760, 2006. PMID: 17051156. DOI: $10.1038 /$ nature 05236

21 Liu Q, Nguyen DH, Dong Q, Shitaku P, Chung K, Liu OY, Tso JL, Liu JY, Konkankit V, Cloughesy TF, Mischel PS, Lane TF, Liau LM, Nelson SF and Tso CL: Molecular properties of cd133+ glioblastoma stem cells derived from treatment-refractory recurrent brain tumors. Journal of Neuro-Oncology 94(1): 1-19, 2009. PMID: 19468690. DOI: 10.1007/s11060-009-9919-z

22 Reya T, Morrison SJ, Clarke MF and Weissman IL: Stem cells, cancer, and cancer stem cells. Nature 414(6859): 105-111, 2001. PMID: 11689955. DOI: 10.1038/35102167

23 Beier D, Rohrl S, Pillai DR, Schwarz S, Kunz-Schughart LA, Leukel P, Proescholdt M, Brawanski A, Bogdahn U, TrampeKieslich A, Giebel B, Wischhusen J, Reifenberger G, Hau P and Beier CP: Temozolomide preferentially depletes cancer stem cells in glioblastoma. Cancer Res 68(14): 5706-5715, 2008. PMID: 18632623. DOI: 10.1158/0008-5472.can-07-6878

24 Prestegarden L, Svendsen A, Wang J, Sleire L, Skaftnesmo KO, Bjerkvig R, Yan T, Askland L, Persson A, Sakariassen PØ and Enger PØ: Glioma cell populations grouped by different cell type markers drive brain tumor growth. Cancer Res 70(11): 4274-4279, 2010. PMID: 20460538. DOI: 10.1158/0008-5472.can-09-3904

25 Kelly JJP, Stechishin O, Chojnacki A, Lun X, Sun B, Senger DL, Forsyth P, Auer RN, Dunn JF, Cairncross JG, Parney IF and 
Weiss S: Proliferation of human glioblastoma stem cells occurs independently of exogenous mitogens. Stem Cells 27(8): 17221733, 2009. PMID: 19544433. DOI: 10.1002/stem.98

26 Avril T, Etcheverry A, Pineau R, Obacz J, Jegou G, Jouan F, Le Reste P-J, Hatami M, Colen RR, Carlson BL, Decker PA, Sarkaria JN, Vauléon E, Chiforeanu DC, Clavreul A, Mosser J, Chevet E and Quillien V: Cd90 expression controls migration and predicts dasatinib response in glioblastoma. Clin Cancer Res 23(23): 7360-7374, 2017. PMID: 28939749. DOI: 10.1158/1078-0432.ccr-17-1549

27 Pollard SM, Yoshikawa K, Clarke ID, Danovi D, Stricker S, Russell R, Bayani J, Head R, Lee M, Bernstein M, Squire JA, Smith A and Dirks P: Glioma stem cell lines expanded in adherent culture have tumor-specific phenotypes and are suitable for chemical and genetic screens. Cell Stem Cell 4(6): 568-580, 2009. PMID: 19497285. DOI: 10.1016/j.stem.2009.03.014

28 Fouse SD, Nakamura JL, James CD, Chang S and Costello JF: Response of primary glioblastoma cells to therapy is patient specific and independent of cancer stem cell phenotype. Neuro Oncol 16(3): 361-371, 2014. PMID: 24311636. DOI: 10.1093/neuonc/not223

29 Kasai N YR: The monoclonal antibody a2b5 is specific to ganglioside gq1c. Brain Res 277(1): 155-158, 1983. PMID: 6640289. DOI: 10.1016/0006-8993(83)90918-6

30 Bao S WQ, Sathornsumetee S, Hao Y, Li Z, Hjelmeland AB, Shi Q, McLendon RE, Bigner DD and Rich JN: Stem cell-like glioma cells promote tumor angiogenesis through vascular endothelial growth factor. Cancer Res 66(16): 7843-7848, 2006. PMID: 16912155. DOI: 10.1158/0008-5472.can-06-1010

31 Guryanova OA WQ, Cheng L, Lathia JD, Huang Z, Yang J, MacSwords J, Eyler CE, McLendon RE, Heddleston JM, Shou W, Hambardzumyan D, Lee J, Hjelmeland AB, Sloan AE, Bredel M, Stark GR, Rich JN and Bao S: Nonreceptor tyrosine kinase bmx maintains self-renewal and tumorigenic potential of glioblastoma stem cells by activating stat3. Cancer Cell 19(4): 498-511, 2011. PMID: 21481791. DOI: 10.1016/j.ccr.2011.03.004

32 Ogden AT WA, Lochhead RA, Fusco D, Lopez K, Ellis JA, Kang J, Assanah M, McKhann GM, Sisti MB, McCormick PC, Canoll P and Bruce JN: Identification of a 2 b5+cd133- tumorinitiating cells in adult human gliomas. Neurosurgery 62(2): 505514; discussion 514-515, 2008. PMID: 18382330. DOI: 10.1227/01.neu.0000316019.28421.95

33 Tchoghandjian A BN, Colin C, Cayre M, Metellus P, Beclin C, Ouafik L and Figarella-Branger D: A2b5 cells from human glioblastoma have cancer stem cell properties. Brain Pathol 20(1): 211-221, 2010. PMID: 19243384. DOI: 10.1111/j.17503639.2009.00269.x

34 Sun T, Chen G, Li Y, Xie X, Zhou Y and Du Z: Aggressive invasion is observed in cd133-/a2b5+ glioma-initiating cells. Oncol Lett 10(6): 3399-3406, 2015. PMID: 26788141. DOI: 10.3892/ol.2015.3823

35 Jhanwar-Uniyal M, Albert L, McKenna E, Karsy M, Rajdev P, Braun A and Murali R: Deciphering the signaling pathways of cancer stem cells of glioblastoma multiforme: Role of AKT/MTOR and MAPK pathways. Adv Enzyme Regul 51(1): 164-170, 2011. PMID: 21035497. DOI: 10.1016/j.advenzreg.2010.09.017

36 Dominici M LBK, Mueller I, Slaper-Cortenbach I, Marini F, Krause D, Deans R, Keating A, Prockop Dj and Horwitz E: Minimal criteria for defining multipotent mesenchymal stromal cells. The international society for cellular therapy position statement. Cytotherapy 8(4): 315-317, 2006. PMID: 16923606. DOI: $10.1080 / 14653240600855905$
37 Kozubenko N TK, Kapcalova M, Butenko O, Anderova M, Rusnakova V, Kubista M, Hampl A, Jendelova P and Sykova E: Analysis of in vitro and in vivo characteristics of human embryonic stem cell-derived neural precursors. Cell Transplant 19(4): 471-86, 2010. PMID: 20021734. DOI: 10.3727/096368909X484707

38 Phillips HS, Kharbanda S, Chen R, Forrest WF, Soriano RH, Wu TD, Misra A, Nigro JM, Colman H, Soroceanu L, Williams PM, Modrusan Z, Feuerstein BG and Aldape K: Molecular subclasses of high-grade glioma predict prognosis, delineate a pattern of disease progression, and resemble stages in neurogenesis. Cancer Cell 9(3): 157-173, 2006. PMID: 16530701. DOI: 10.1016/j.ccr.2006.02.019

39 Wei W SQ, Remacle F, Qin L, Shackelford DB, Shin YS, Mischel PS, Levine RD and Heath JR: Hypoxia induces a phase transition within a kinase signaling network in cancer cells. Proc Natl Acad Sci USA 110(15): E1352-60, 2013. PMID: 23530221. DOI: $10.1073 /$ pnas. 1303060110

40 Dirkse A, Golebiewska A, Buder T, Nazarov PV, Muller A, Poovathingal S, Brons NHC, Leite S, Sauvageot N, Sarkisjan D, Seyfrid M, Fritah S, Stieber D, Michelucci A, Hertel F, HeroldMende C, Azuaje F, Skupin A, Bjerkvig R, Deutsch A, VossBohme A and Niclou SP: Stem cell-associated heterogeneity in glioblastoma results from intrinsic tumor plasticity shaped by the microenvironment. Nat Commun 10(1): 1787, 2019. PMID: 30992437. DOI: 10.1038/s41467-019-09853-z

41 Wang J, O'Bara MA, Pol SU and Sim FJ: Cd133/cd140a-based isolation of distinct human multipotent neural progenitor cells and oligodendrocyte progenitor cells. Stem Cells Dev 22(15): 21212131, 2013. PMID: 23488628. DOI: 10.1089/scd.2013.0003

42 Golebiewska A, Bougnaud S, Stieber D, Brons NHC, Vallar L, Hertel F, Klink B, Schrock E, Bjerkvig R and Niclou SP: Side population in human glioblastoma is non-tumorigenic and characterizes brain endothelial cells. Brain 136(5): 1462-1475, 2013. PMID: 23460667. DOI: 10.1093/brain/awt025

43 Wang Q, Hu B, Hu X, Kim H, Squatrito M, Scarpace L, deCarvalho AC, Lyu S, Li P, Li Y, Barthel F, Cho HJ, Lin YH, Satani N, Martinez-Ledesma E, Zheng S, Chang E, Sauve CG, Olar A, Lan ZD, Finocchiaro G, Phillips JJ, Berger MS, Gabrusiewicz KR, Wang G, Eskilsson E, Hu J, Mikkelsen T, DePinho RA, Muller F, Heimberger AB, Sulman EP, Nam DH and Verhaak RGW: Tumor evolution of glioma-intrinsic gene expression subtypes associates with immunological changes in the microenvironment. Cancer Cell 32(1): 42-56 e46, 2017. PMID: 28697342. DOI: 10.1016/j.ccell.2017.06.003

44 Friedman MD, Jeevan DS, Tobias M, Murali R and JhanwarUniyal M: Targeting cancer stem cells in glioblastoma multiforme using mtor inhibitors and the differentiating agent all-trans retinoic acid. Oncol Rep 30(4): 1645-1650, 2013. PMID: 23877261. DOI: 10.3892/or.2013.2625
Received December 16, 2020

Revised January 24, 2021

Accepted January 262021 